\title{
Art in Fracture: The making of the new cover for Theoretical and Applied Fracture Mechanics
}

Readers will have noticed that this journal has a new cover. Early in 2013, Luca Susmel contacted me, asking if I would be interested in painting a picture to be used as part of the cover design. As a researcher in the field of fracture mechanics, with pretensions towards being an artist, I was very glad to accept the challenge. This article describes the discussions and activities that went into the making of the finished piece of work.

At the start, Luca and I exchanged ideas about what would be required, trying to find a set of criteria for the project. How to represent the work and aims of the journal, and the broader topic of fracture mechanics, in both its theoretical and applied aspects? Examples of works of art were exchanged, including paintings from the Futurist and Cubist movements which expressed positive images of industrial and scientific progress and also incorporated fractured picture planes and interrupted images. I also looked at the covers of other journals. Many journal covers are very simple and, quite frankly, rather boring, but some are very inspiring. For example the juxtaposed images on the cover of Medical Hypotheses and the lively, mobile graphic design of Applied Animal Behaviour Science.

Two requirements became clear from an early stage. Firstly, there should be a crack in the picture. Cracks are so central to fracture mechanics: the very idea that materials fail by cracking is the defining concept which marks the emergence of our subject. The understanding of crack initiation and growth continues to be a major research activity. Secondly, whatever image was created would have to "work" not only in its full size on the cover of the printed journal, but also in the reduced size at which it appears on the website and on the title page of each individual paper. These days very few people have the printed journal in their hands, so the small image has become all the more important as a representation of the journal.

Work began with sketches using pencil, charcoal, ink and watercolours. Initially, many different ideas were considered: Fig. 1 shows a selection of these. The idea of showing examples of modern engineering - aircraft, ships, buildings, etc. - with an introduced element of fracture, seemed an attractive concept, but my pictures just kept coming out like posters for a disaster movie! Fracture mechanics test specimens can make nice graphic images with their strong geometric shapes (see Fig. 2) but the result showed nothing of the theoretical side of our subject.

I realised that bringing in the idea of theoretical research was a key problem to solve. So how to express the idea of theory in a visual form? One obvious way is to use equations. We express theoretical concepts through equations and fracture mechanics has developed some key formulae which everyone in the field would immediately recognise. Reproducing them would also be a way of honouring major figures in our field such as Rice and Griffith. Computer simulations - especially finite element analysis - also provide attractive images of theory in action. But some more general, more philosophical ideas also came to mind, such as the image of an eye, to represent looking at a problem and, by extension, thinking about it, and the concept of "shedding light" on a problem.

My initial sketches and ideas were whittled down to three possible designs, which were then realised in more detail, making use of two different formats: paintings using acrylic paint on canvas and computer graphics images created using Microsoft Visio (see Fig. 3). The first design expressed the idea of theory using the image of an eye, with a crack entering the eye. This crack also looks rather like a flash of lightening, suggesting a moment of inspiration. The second design involved painting the cover of the journal as if it was being ripped apart, creating a crack in the paper and revealing equations in the page beneath. I also rather liked the (slightly controversial?) implication here that the paper copy of a journal is now redundant, as it is increasingly being replaced by the electronic format. The third design used the "shedding light" concept, with a spotlight shining onto a crack in a test specimen.

After considering these suggestions Luca came back to me to say that he liked two of them - the ripped cover and the spotlight, but asking if I could find a way to combine both ideas in the same picture. This taught me a lesson as an artist: never give the client a choice! But actually Luca's response provided a challenge which I'm sure improved the final product. This was realised in two different paintings (Fig. 4). Luca decided to use the more threedimensional picture, rather than the flatter, stylised image. I think his main reason was that, from the outset, he had wanted to have a journal cover which featured a painting, rather than the kind of graphic image which is more common in cover design.

I hope that you like my painting, and I'd be glad to hear from you if you have any opinions about it. I don't expect that everyone will like it, but I'd be interested to hear how people react to it. What do you think should be on the cover of the journal? And do you think it matters what's on the cover? Some people are interested in art, spending a lot of time in art galleries and maybe even buying works of art themselves. Others are not so interested, but visual art is something which nobody can ignore, because it's all around us: on the covers of books, on advertising hoardings and the packaging of products, in the architecture of buildings. I for one would not like to live in a world with no art, and that's not 

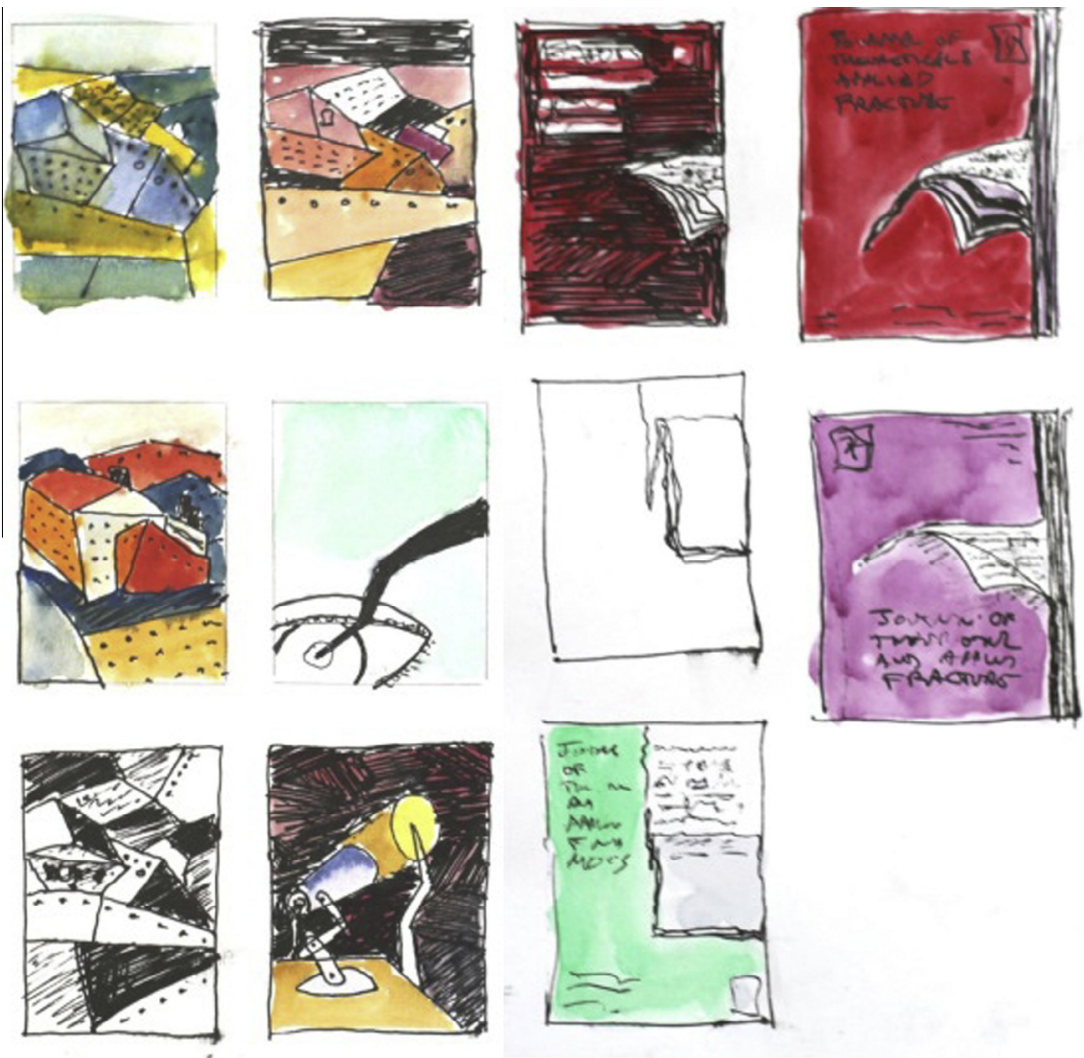

Fig. 1. Some of the many sketches generated during the initial phase of the work. These were made using an ink pen and watercolours.

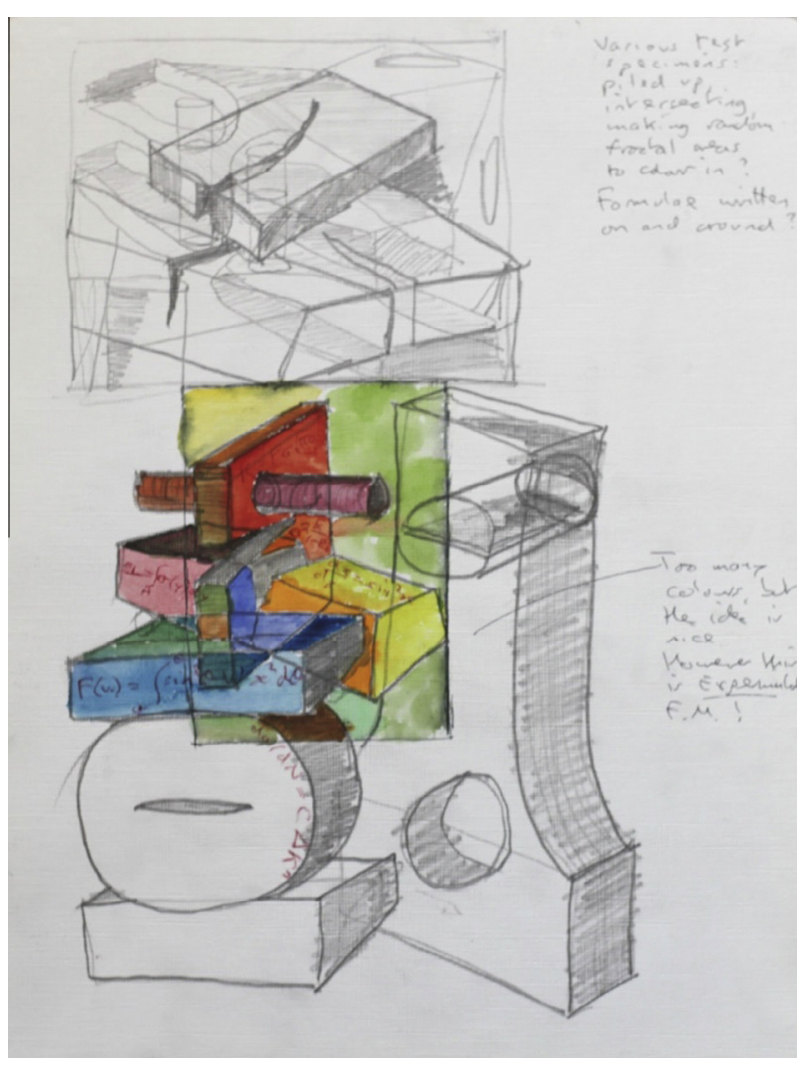

Fig. 2. Pencil and watercolour sketches working with the idea of test specimens.

likely to happen because as a species we seem to have an instinct for creating visual representations of the world: cave paintings show that we've been doing it for a long time, probably since before we had a spoken language.

What is the purpose of the artwork on the cover of a scientific journal? I would say that it's one of many elements which contribute to give the journal a unique character and identity. I am the editor-in-chief of a journal myself, and something which often comes up in discussion with my fellow editors and with the publishers, Elsevier, is the question of how the journal is perceived by the various people involved with it. The readers, authors, reviewers and board members all identify with a journal to varying degrees: we hope that they will form a favourable impression of the journal, effectively becoming "stakeholders" who will help the journal to be a success. Some aspects of a journal's performance are obviously important and relatively easy to quantify, such as the Impact Factor, speed of reviewing, and novel technical features such as the acceptance of additional content files. Other factors are less easy to quantify but can make a real difference: examples are how the personnel on the journal respond to queries and complaints, the ease of use of the website, and (who knows?) perhaps even the picture on the cover.

I am involved in a number of projects which combine art and science and I find these activities to be very stimulating and actually quite helpful for my regular research work. Scientists and engineers are creative people; we have to be constantly innovating in order to come up with new ideas, new methods and new products. But the creative process is not strongly emphasised in our education or actively fostered in our working environment. Professional artists, on the other hand, spend a lot of time thinking about personal creativity and finding ways to stimulate and control the creative act. For me this project has been a rare opportunity to combine my artistic and scientific interests; I'd like to thank Luca Susmel very much and wish him great success as editor-in-chief of the journal. 


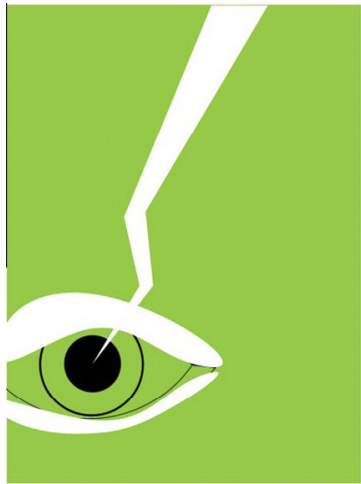

(a)

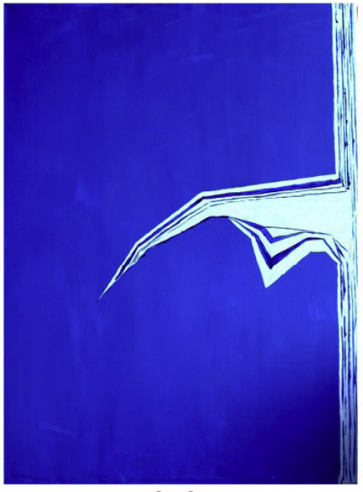

(b)

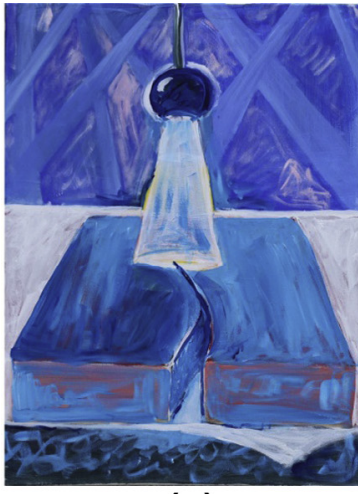

(c)

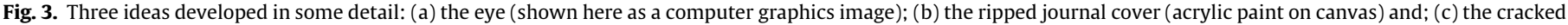
specimen and spotlight (also acrylic on canvas).
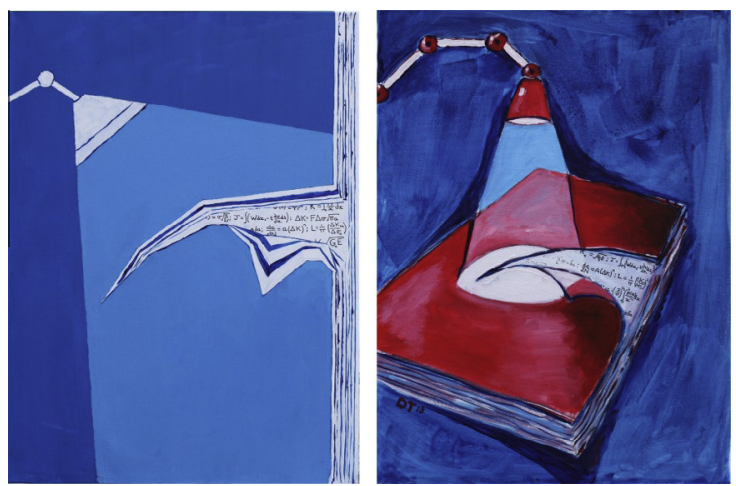

David Taylor

Engineering School,

Trinity College Dublin, Ireland

Tel.: +3531 6081703; fax: +35316795554.

E-mail address: dtaylor@tcd.ie

Available online xxxx

Fig. 4. The two final candidate paintings. 